\title{
Polymer Concrete Made With Recycled Glass Aggregates, Flyash and Metakaolin
}

\author{
Shaik. Khazamohiddin \\ Prof.K.Nitya, Vellore Institute Of Technologies
}

\begin{abstract}
A novel polymer concrete (PC) was synthesized by mixing epoxy resins and waste glass as aggregates. In this study, metakaolin (MK) and fly ash (FA) were used as filler and compositions with $0 \%, 10 \%$ and $15 \%$ by weight of recycled glass sand $(<2.36 \mathrm{~mm})$ were prepared to investigate the mechanical and durability properties of the PC. The results indicated that all compositions assessed in this study display high strength and modulus of elasticity values. MK and FA have a significant effect on the compressive strength, the flexural strength and the modulus of elasticity of the PC. Moreover, the PC made with recycled glass aggregate, $\mathrm{MK}$ and $\mathrm{FA}$ has good chemical resistance for $20 \% \mathrm{Na} 2 \mathrm{CO} 3,10 \% \mathrm{NaOH}$, tap water, and sea water. Besides the acceptable chemical resistance, the prepared waste glass PC shows low apparent porosity and low water absorption.
\end{abstract}

Keywords: Polymer, metakaolin, flyash, recycled waste glass, quartz sand

\section{Introduction:}

The reuse and recycling of solid waste has raised great concern to reduce waste disposal. Glass, being one of the major solid wastes, has been investigated as to its ability to be recycled, reproduced and reused. Which make the glass unfavorable for glass bottle production? Hence, researchers have been looking for another outlet for this waste glass. As glass is basically similar to sand, which is one of the major elements in concrete, research experts have been trying to use recycled glass in concrete to replace aggregate. If glass is proved to be feasible and workable in concrete, the recycling and reuse of this waste can be improved and hence the volume of wastes disposed of in landfills can be reduced.

A number of studies have been carried out for use recycled glass in civil engineering. The crushed glass can be classified as well graded sands with gravel (SW) and exhibited excellent strength and workability characteristics. The low specific gravity (2.49) contributed to crushed glass having compacted maximum dry densities on the order of $16.6-16.8$ and $17.5-18.3 \mathrm{kN} / \mathrm{m}^{3}$ by the standard and modified proctor compaction tests, respectively.

It undergoes beneficial pozzolanic reactions in the concrete and could replace up to $30 \%$ of cement in some concrete mixes with satisfactory strength development. Polymer concrete (PC) is a composite material produced by combining dry aggregates, in which the monomers (binders) undergo polymerization (hardening) after the addition of Additives, catalysts and accelerators. Due to its rapid setting, high strength properties and ability to withstand a corrosive environment, Polymer-based building materials have received special attention. Coarse and fine aggregates, such as crushed stone, sand, gravel, and fly ash, which result as a waste from thermal power plants, are widely used as inorganic fillers in the production of PC .Good mechanical properties and the excellent chemical resistance of polymer concretes make them cost-effective construction materials for civil engineering applications. These properties of polymer concretes are dependent upon the type of polymeric binder and the filler materials used. The effectiveness of fly ash in PC is well-known. Fly ash improves the workability of fresh PC mortar and the resulting concrete shows excellent surface finish .The small size of spherical fly ash particles also contributes to a better packing of the aggregate materials, which reduces porosity and hinders the penetration of aggressive agents, thus considerably improving the chemical resistance of PC.

Metakaolin (MK) is produced from kaolinite clay through a calcining process. Many Portland cement concrete mixing companies already use very successfully the pozzolanic characteristics of MK as a replacement for cement in their mix design (i.e. as a mineral admixture). An advantage of MK over other pozzolans is that MK is a primary product, not a secondary product or by-product. This allows the manufacturing process to be structured to pro-duce the optimum characteristics for MK, ensuring the production of a consistent supply. Another advantage of MK is its colour, which is white and produces much lighter colored PC for decorative construction panels.

The aim of this work is to study the suitability of PC prepared with recycled waste glass aggregate to be used as polymer-based building material, and to report on the properties such as compressive strength, flexural strength, modulus of elasticity of the PC prepared with MK and FA. 


\section{Experimental program:}

\section{Materials and specimens preparation:}

The mix design for the PC systems is optimized for workability, strength and economy, depending on the intended application The epoxy resin system used is based on a diglycidyl ether bisphenol A and an aliphatic amine hardener with low viscosity (500-700 MPa s) and flexural strength of $70 \pm 5 \mathrm{MPa}$, which cluster the waste glass aggregate. In this study, the resin content used was $13 \%$ by weight. The coarse aggregate was recycled glass $(10-5 \mathrm{~mm})$, whereas the fine aggregates were recycled glass sand $(<2.36 \mathrm{~mm})$, fly ash (FA) and metakaolin (MK). The coarse recycled glass aggregate and recycled glass sand was oven-dried for a minimum of $24 \mathrm{hrs}$ to reduce their moisture content to less than $0.5 \%$ by weight, thus ensuring good adhesion between the polymer matrix and the aggregates. The particle size distribution of coarse recycled glass aggregate and recycled glass sand are shown in The major trace components of the MK and FA used in this study are also shown and the mix proportions of the PC are shown in Mixing was typically done using conventional concrete mixers for a period of about $5 \mathrm{~min}$. Specimens were then cast in steel moulds with $15^{*} 15 \mathrm{~cm}$ cube $75^{*} 150 \mathrm{~mm}$ cylinders and $40 * 40 * 160 \mathrm{~mm}$ prisms.

In order to investigate the effect of casting pressure on the compressive strength of the $\mathrm{PC}$, after control specimens are cast in steel moulds with $75150 \mathrm{~mm}$ cylinders, a compression force from 3 to $12 \mathrm{kN} / \mathrm{cm}^{2}$ was applied for $60 \mathrm{~s}$ to allow curing at room temperature.

\section{MATERIALS FOR POLYMER CONCRETE:}
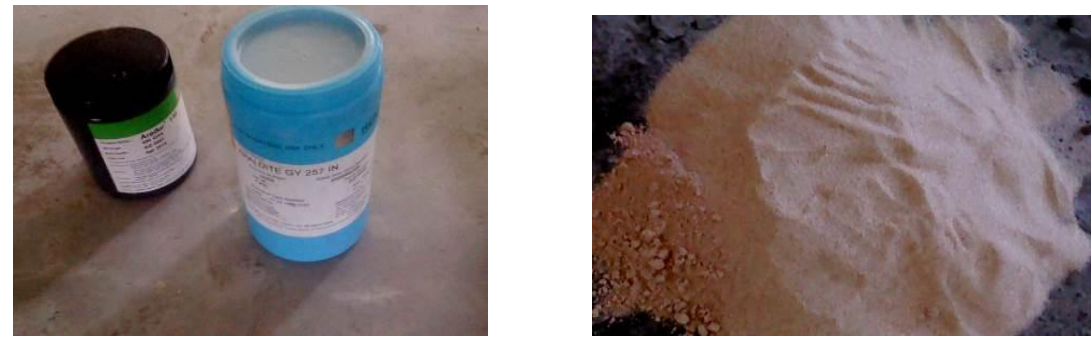

1. Diglycidyl ether bisphenol A and an aliphatic amine hardener
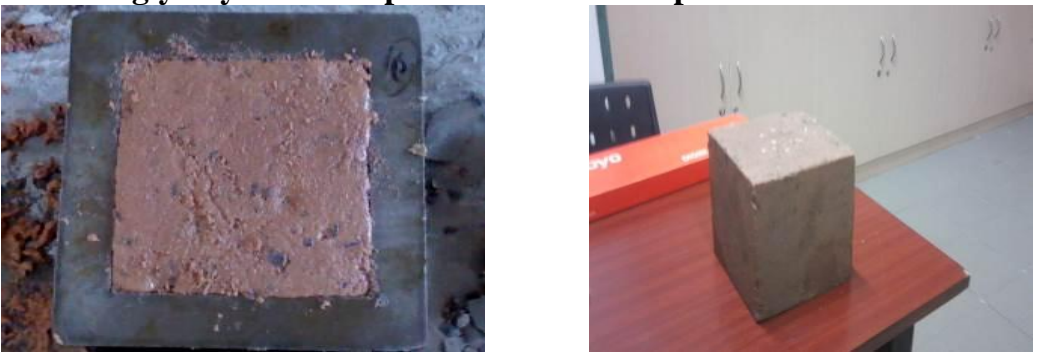

Trace components of Metakaolin and Flyash: Table1:

\begin{tabular}{|l|r|r|r|}
\hline component & FLYASH (\%) & METAKAOLIN (\%) \\
\hline $\mathrm{Al}_{2} \mathrm{O}_{3}$ & & 28.21 & 43.9 \\
\hline $\mathrm{SiO}_{2}$ & & 56.79 & 53.2 \\
\hline $\mathrm{Na}_{2} \mathrm{O}$ & - & 0 & 0.17 \\
\hline $\mathrm{TiO}_{2}$ & $<$ & & 1.68 \\
\hline $\mathrm{CaO}$ & & 5.31 & 0.02 \\
\hline $\mathrm{Fe}_{2} \mathrm{O}_{3}$ & & 5.21 & 0.38 \\
\hline $\mathrm{MgO}^{\mathrm{N} O}$ & & 0.05 \\
\hline $\mathrm{K}_{2} \mathrm{O}$ & - & 3.9 & 0.1 \\
\hline Ignition loss & & 0.5 \\
\hline
\end{tabular}




\section{METAKAOLIN EFFECT:}

\section{CONCRETE USE $=7 \%$ GLOBAL (Co2) EMMISIONS}

Cement, which is mostly commonly composed of calcium silicates, requires heating limestone and other ingredients to 2,640 degrees $\mathrm{F}$ (1,450 degrees $\mathrm{C}$ ). Even more $\mathrm{CO}_{2}$ is produced from the reaction caused by burning the limestone. The kaolin clay to metakaolin reaction, however, does not produce any $\mathrm{CO}_{2}$.In addition, the Whitemud kiln temperature of $800{ }^{\circ} \mathrm{C}$ is just over half the $1500{ }^{\circ} \mathrm{C}$ required to produce cement clinker, reducing energy requirements and greenhouse gas emissions.

Use of metakaolin: Boost compressive strength; Make finishing easier, Reduce efflorescence, Mitigate alkalisilica reaction, and Maintain color, especially in white concrete

How does metakaolin boost compressive strength: Calcium hydroxide accounts for up to $25 \%$ of the hydrated Portland cement, and calcium hydroxide does not contribute to the concrete's strength or durability? Metakaolin combines with the calcium hydroxide to produce additional cementing compounds, the material responsible for holding concrete together. Less calcium hydroxide and more cementing compounds means stronger concrete.

1. Alkali-silica reaction is a reaction between calcium hydroxide (the alkali) and glass (the si which can cause decorative glass embedments in concrete to pop out. Because metakaolin consumes calcium hydroxide, it takes away the alkali and the reaction does not occur.

2. How do I use metakaolin: Previous experience has shown that optimal performance is achieved by replacing $10 \%$ to $15 \%$ of the cement with metakaolin. While it is possible to use less, the benefits are not fully realized until at least $10 \%$ metakaolin is used.

\section{Testing:}

\section{Compressive strength and modulus of elasticity:}

PC compression tests were performed on $75150 \mathrm{~mm}$ cylinders at the loading rate of $1.25 \mathrm{~mm} / \mathrm{min}$ according to the ASTM C39-05 standard. The compression specimen was tested in a compression machine with a loading capacity of $3000 \mathrm{kN}$ Electrical strain gauges bonded to the specimens and connected to a data acquisition system were used to read strains for modulus of elasticity evaluation.

\section{Flexural strength}
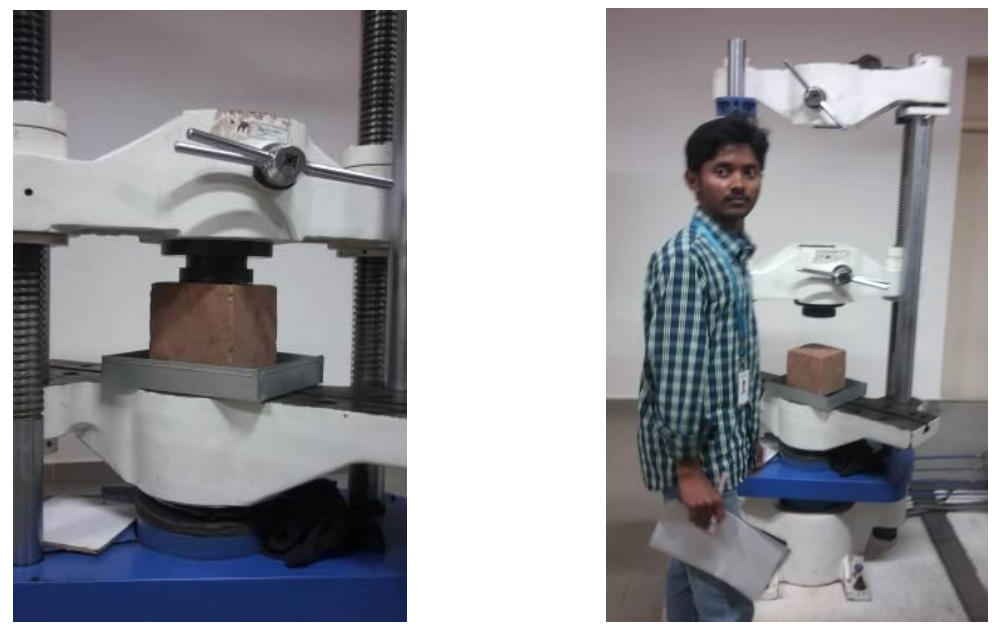

A three-point bending test, which according to RILEM PCM8 is a "Method of test for flexural strength and deflection of polymer-modified mortar" was performed on $75^{*} 150 \mathrm{~mm}$ cylindrical specimens.

\section{Chemical resistance}

The chemical resistance of the samples were tested following the ASTM D543-06 ] for immersing the weighted, cured PC prisms with a size of $75 * 150 \mathrm{~mm}$ in different solutions for different periods of time to determine the flexural strength as well as through visual inspection to observe any physical defects, cracks, changes of appearance or colour. The test specimens were measured in tap water, ground water, seawater, $20 \%$ $\mathrm{Na}_{2} \mathrm{CO}_{3}, 10 \% \mathrm{NaOH}$ and $10 \% \mathrm{H}_{2} \mathrm{SO}_{4}$. The concentration of some ions of interest in tap water and seawater are presented in table. 


\begin{tabular}{|c|c|c|c|c|c|c|c|}
\hline \multicolumn{5}{|c|}{$\begin{array}{l}\text { Title::Mix proportion and strength development ratio of } \\
\text { polymer concrete: }\end{array}$} & TABLE:2 & \multirow[b]{2}{*}{$\begin{array}{l}\mathrm{f}_{\mathrm{c} 1} / \mathrm{f}_{\mathrm{c} 2} \\
8(\%)\end{array}$} & \multirow[b]{2}{*}{$\begin{array}{l}\mathrm{f}_{\mathrm{c} 4} / \mathrm{f}_{\mathrm{c}} \\
28 \\
(\%)\end{array}$} \\
\hline Notation & $\begin{array}{l}\text { MK } \\
(\%)\end{array}$ & $\begin{array}{l}\text { FA } \\
(\%)\end{array}$ & $\begin{array}{l}\text { Resin } \\
(\%)\end{array}$ & $\begin{array}{r}\text { Waste glass }(\%)(10-5 \\
\mathrm{mm})\end{array}$ & $\begin{array}{l}\text { Waste glass } \\
\text { sand }(\%) \\
(<2.36 \mathrm{~mm})\end{array}$ & & \\
\hline Control & 0 & 0 & 13 & $\begin{array}{l}2 \\
2\end{array}$ & 65 & 74.9 & 84.4 \\
\hline PC-M10 & 10 & - & 13 & $\begin{array}{l}2 \\
2\end{array}$ & 55 & 74.7 & 84.7 \\
\hline PC-M15 & 15 & - & 13 & $\begin{array}{l}2 \\
2\end{array}$ & 50 & 74.5 & 86.3 \\
\hline PC-F10 & - & 10 & 13 & $\begin{array}{l}2 \\
2\end{array}$ & 55 & 75.8 & 85.9 \\
\hline PC-F15 & - & 15 & 13 & $\begin{array}{l}2 \\
2\end{array}$ & 50 & 76.3 & 87.1 \\
\hline & & & & & & & \\
\hline
\end{tabular}

\section{Compressive strength:}

\section{Results and discussion:}

\section{Effect of casting pressure on compressive strength:}

The effect of applied casting pressure on the mechanical proper-ties of the control mixture was studied by casting cylinders of PC synthesized from recycled glass waste under different casting pressures and the results obtained are presented in Fig. It is seen that casting the PC under pressure above atmospheric pressure was accompanied by a detectable enhancement in compressive integrity of the final products. This may be attributed to the effect of applied pressure ejecting the voids between the filler particles in the cast PC, and hence the cylinders becoming more compacted and rigid However, it should be noted that increasing the applied pressure from 6 to $12 \mathrm{kN} / \mathrm{cm}^{2}$ corresponded to slight changes in the compressive strength values of the cast PC. That means when applied pressure reached $6 \mathrm{kN} / \mathrm{cm}^{2}$, the voids between the filler particle were nearly completely released. The mechanical proper-ties for various polyester-filler composites depend on the type and amount of filler and also on the particle size of the filler used.

\section{Effect of MK and FA on compressive strength:}

The development of the compressive strength of PC with curing age is presented in Fig.The ratios of the strength development are shown in Table. It is found that about $75 \%$ of its final strength was obtained after 1 day of curing. On the other hand about $85 \%$ of its final strength was reached within only 4 days. These results could be compared to that of cement concrete where about $20 \%$ of its final strength is achieved after 1 day and about $80 \%$ of its final strength after 28 days. In the precast components, the fast cure time of the material permits the structures to resist large stresses due to transportation and erection operations. This is advantageous in PC, which can be applied overnight and the structure can be returned to traffic the next morning.

It is also observed that the PC compositions showed an increase in compressive strength as the concentration of MK or FA in-creased. The replacement of $10 \%$ and $15 \%$ by weight of recycled glass sand with metakaolin typically results in about $18 \%$ and $26 \%$ increases in compressive strength compared to control PC, respectively. Moreover, the replacement of $10 \%$ and $15 \%$ by weight of recycled glass sand with fly ash results in about $25 \%$ and $36 \%$ in-creases in compressive strength, respectively.

The reason for this occurrence may be the fact that FA or MK achieves better workability than recycled glass sand. The fine particles of MK or FA provide the fresh PC mix with improved lubricating properties, thus improving its plasticity and cohesiveness. The use of MK or FA may also produce optimum packing conditions for the different aspect ratios of recycled glass sand and MK or FA during casting, thus resulting in a more homogeneous and compact final PC product. There are also other important advantages of using MK or FA as a filler in PC. MK or FA is usually obtained dry from suppliers. Therefore, it may not need to be oven-dried to ensure good adhesion with the polymer matrix, which is not the case with coarse recycled glass aggregate and recycled glass sand. Also MK provides PC with a white colour and an improved smooth surface appearance.

\section{Modulus of elasticity}

The setup of testing of the modulus of elasticity is shown in Fig. The results of modulus of elasticity of PC mixtures are shown in Fig. It can be seen that the modulus of elasticity of the PC imp-proves after the addition of both MK and FA. The replacement of $10 \%$ and $15 \%$ by weight of recycled glass sand with 
metakaolin typically results in about $11 \%$ and $18 \%$ increases in modulus of elastic-city, respectively. Moreover, the replacement of $10 \%$ and $15 \%$ by weight of recycled glass sand with fly ash typically results in about $20 \%$ and 30\% increases in modulus of elasticity, respectively. The PC prepared with FA had a higher increase in modulus of elasticity than the corresponding PC with MK, which might be due to the "filler effect" of FA being higher than that of MK. Furthermore, at the same replacement level of recycled glass sand with fly ash, the amount of increase in modulus of elasticity is small in comparison the increase in compressive strength.

\section{FIGURES:}

\section{Load vs Elongation:}

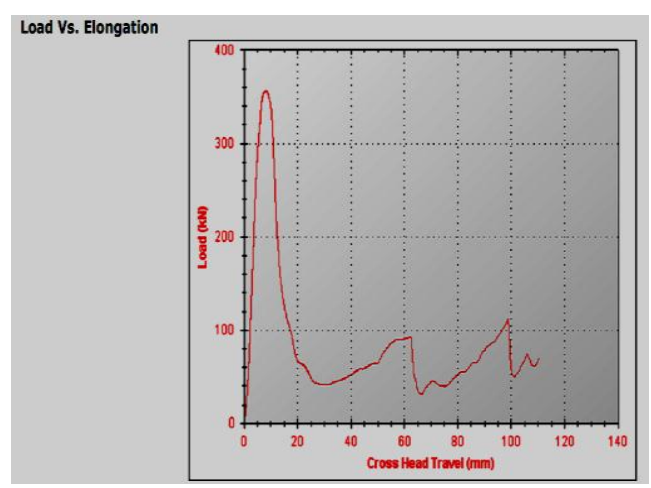

\section{Load vs Time:}

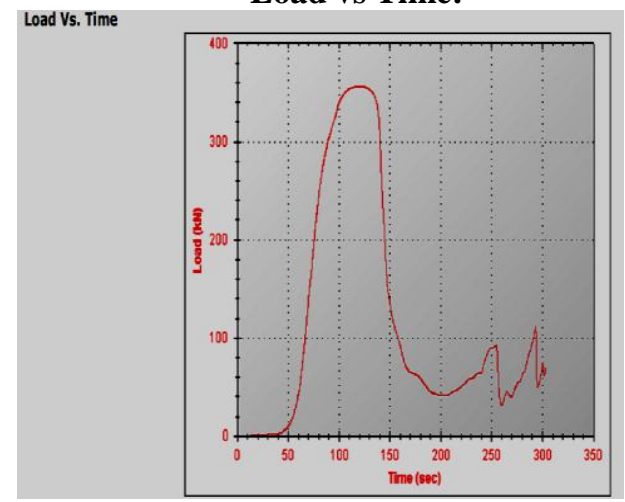

Compressive strength comparision

Compressive strength vs time (days)

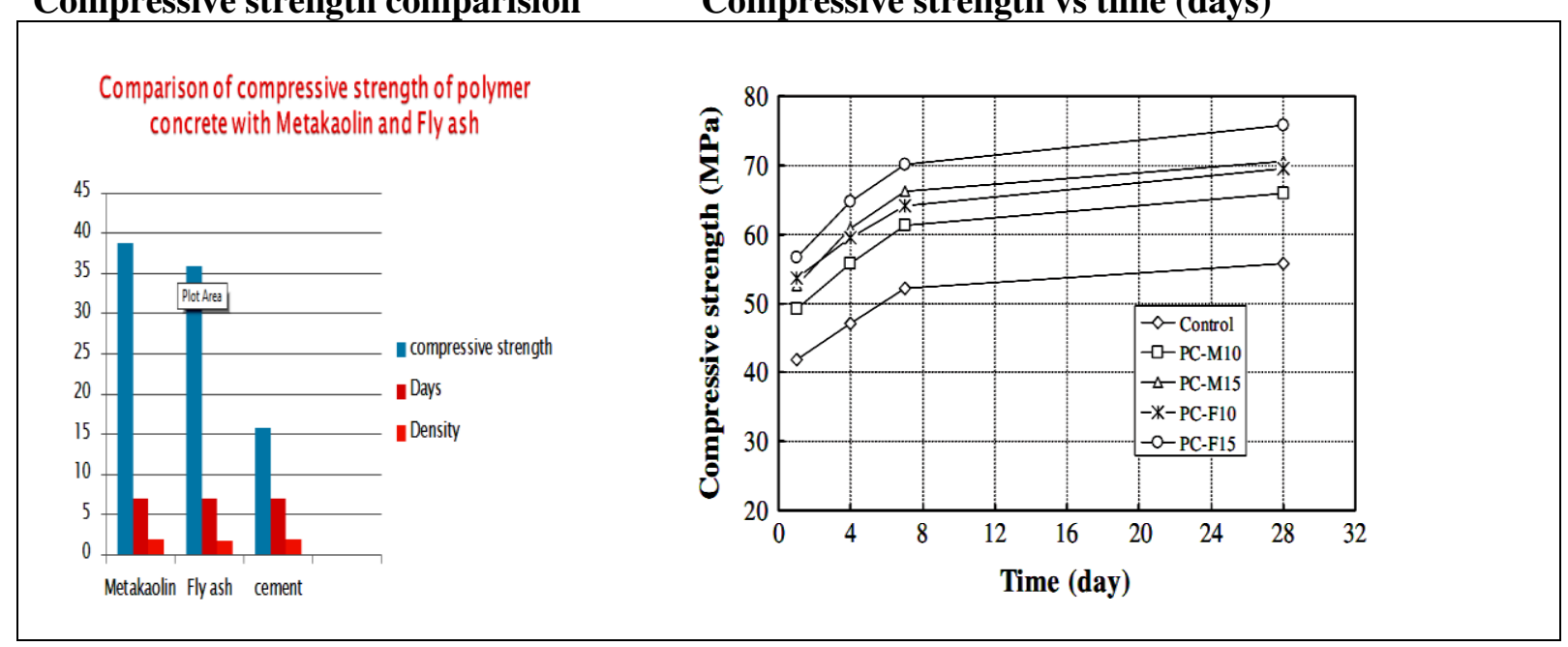

MIX NOTATION VS FLEXURAL STRENGTH

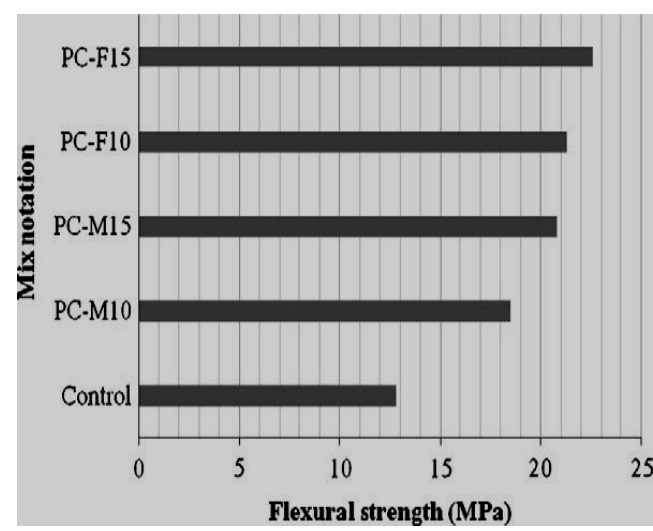

MODULUS OF ELASTICITY VS MIX NOTATION

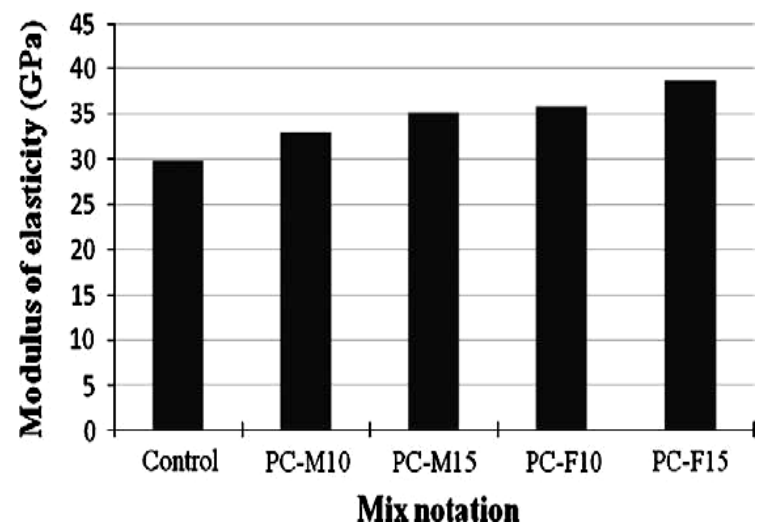

\section{Flexural strength}

Fig.shows how the concentration of fly ash and metakaolin affect the flexural strength. The values obtained here are similar to those reported in the literature] and show that the PC has excellent flexural strength. 
The flexural strength of the PC prepared with MK and FA was higher than that of the control PC. It is also observed that the PC compositions showed an in-crease in flexural strength as the concentration of MK or FA increased. Moreover, a higher increase in flexural strength was obtained for the PC made with FA compared to MK.

\section{Conclusions:}

Based on the results presented, it can be concluded that:

(1) A fast cured PC can be synthesized with recycled glass waste materials which have acceptable physical proper-ties, good mechanical integrity and enhanced chemical characterization.

(2) MK and FA can improve some recycled glass PC properties, the most notable ones being the strengths and modulus of elasticity of PC.

(3) The production of the recycled glass PC mentioned can be developed on semi-industrial and industrial scales for its economic advantages, as well as environmental benefits.

(4) The good strength properties of PC using MK, FA and recycled glass aggregate make the material attractive in a number of applications which include hollow median barriers in roads that are filled with normal concrete at the site to pro-vide mass, building panels that are produced as both single skin and sandwich panels, and attractive floor blocks or tiles, especially for decorative industrial applications.

The values observed in this study are quite high if compared with Portland cement concrete, including high-strength types. Found a mean of 5.56 MPa for flexural strength with the addition of $20 \%$ of fly ash and a w/b ratio of 0.48 ., obtained compressive strength values of $85.1 \mathrm{MPa}$ in a sample with a flexural strength of 9.7 $\mathrm{MPa}$. Moreover, in this study the ratio of flexural strength to compressive strength of $24.7-29.8 \%$ is obtained. However, in Portland cement concrete, flexural strength values correspond to approximately $10 \%$ of those of compressive strength.

The good strength properties of PC using MK, FA and recycled glass aggregate make the material attractive in a number of applications. Examples include hollow median barriers in roads that are filled with normal concrete at the site to provide mass, building panels that are produced as both single skin and sandwich panels, and attractive floor blocks or tiles, especially for decorative industrial applications

\begin{tabular}{|l|l|l|l|l|l|l|}
\hline & Table-3: & & \\
\hline
\end{tabular}

\section{References:}

[1]. Varughese KT, Chaturvedi BK. Fly ash as fine aggregate in polyester based polymer concrete. Cem Concr Compos 1996; 18:105-8.

[2]. Abdul Razak H, Wong HS. Strength estimation model for high-strength concrete incorporating metakaolin and silica fume. Cem Concr Res 2005; 35:688-95.

[3]. Srivastava A, Aggarwal RK, Singh P. Building materials based on polymers — an overview. Popular Plast Package 2001; 46:62.

[4]. Rebeiz KS, Fowler DW. Recycling plastics in polymers concrete systems for engineering applications. Polymer Plast Technology Eng. 1991; 30:809.

[5]. Meyer C, Baxter S, Jin W. Alkali-silica reaction in concrete with waste glass as aggregate. Materials for the new millennium proceedings of the materials engineering conference, New York, NY, USA: ASCE 1996; 2:1388-97.

[6]. Shayan A, Xu A. Value added utilization of waste glass in concrete. Cem Concr Res2004; 36(3):457-68.

[7]. J.A. Mason, "Applications in Polymer Concrete". ACI Publication SP-69, American Concrete Institute, Detroit, Michigan, 1981.

[8]. J.T. Dikeou, "Polymers in Concrete: New Construction Achievements on the Horizon". Proceedings, Second International Congress on Polymers in Concrete, Austin, Texas, October 1978.

[9]. M. Steinberg et al., "Concrete-Polymer Materials", First Topical Report, Brooklyn National Laboratory, BLN 50134 (T-509), 1968; U.S. Bureau of Reclamation, USBR General Rept. 41, 1968.

[10]. C.D. Pomeroy and J.H. Brown, "An Assessment of some Polymer (PMMA) Modified Concretes". Proceedings, First International Congress on Polymers in Concretes, London, U.K., May 1975. 
[11]. J. Pietrzykowski, "Polymer-Concrete Composites". IASBE Proceedings P-38/81, 1981.

[12]. http://genevapolymerproducts.com

[13]. Design and manufacture of hybrid polymer concrete bed for high-speed CNC milling machine Jung Do Suh Æ Dai Gil Lee

[14]. The compressive strength of a new ureaformaldehyde-based polymer concrete A. A. Alzaydi, S. A. Shihata1 and T. Alp (in table Properties of polymer concrete) 